\title{
Pharmacokinetic Interaction Between Oltipraz and Silymarin in Rats
}

\author{
Min Kyung Kang ${ }^{1}$, Soo Kyung Bae ${ }^{1 \S}$, Jin Wan Kim ${ }^{2}$, Myung Gull Lee ${ }^{1}$ \\ ${ }^{1}$ College of Pharmacy and Research Institute of Pharmaceutical Sciences, Seoul National University, Seoul, South Korea; \\ ${ }^{2} \mathrm{R} \&$ D Center of Pharmaceuticals, Institute of Science \& Technology, CJ Corporation, Ichon, South Korea
}

Received, December 23, 2008; Revised, January 9, 2009; Accepted, January 23, 2009; Published, January 25, 2009

\begin{abstract}
Purpose: To evaluate the pharmacokinetic interaction between oltipraz and silymarin after intravenous and oral administration of both drugs to male Sprague-Dawley rats. Methods: Oltipraz (single doses of 10 and $30 \mathrm{mg} / \mathrm{kg}$ for intravenous and oral administration, respectively), silymarin (single doses of 50 and $100 \mathrm{mg} / \mathrm{kg}$ for intravenous and oral administration, respectively, and 14 days oral administration of 100 $\mathrm{mg} / \mathrm{kg}$ ), alone and together were administered to control rats. Results: The pharmacokinetic parameters of oltipraz did not significantly altered by silymarin. However, after intravenous administration of the drugs together, the AUCs of unconjugated, conjugated, and total (unconjugated plus conjugated) silibinin were significantly different (32.7\% decrease, and $32.1 \%$ and $27.2 \%$ increase, respectively), and total and (CL) and non-renal $\left(\mathrm{CL}_{\mathrm{NR}}\right)$ clearance of unconjugated silibinin were significantly faster $(49.4 \%$ and $61.1 \%$ increase, respectively) than those of silymarin alone (without oltipraz). After oral administration of silymarin with or without oltipraz, however, the pharmacokinetic parameters of unconjugated, conjugated, and total silibinin were comparable. Conclusions: After single intravenous administration of the drugs together, the AUC of unconjugated silibinin was significantly smaller, but that of both conjugated and total silibinin was significantly greater. This could have been due to an increase in the formation of conjugates (glucuronidation and sulfation) of silibinin as induced by oltipraz. After simultaneous oral administration of the drugs, however, the AUCs (or $\mathrm{AUC}_{0-12 \mathrm{~h}}$ ) of unconjugated, conjugated, and total silibinin were comparable.
\end{abstract}

\section{INTRODUCTION}

Oltipraz [5-(2-pyrazinyl)-4-methyl-1,2-dithiol-3thione], a synthetic dithiolthione, (Rhône-Poulenc, Virty-sur-Seine, France) is used for the treatment of schistosomiasis (1). The cancer chemopreventive activities of oltipraz against aflatoxin-induced tumorigenesis in rats (2), and therapeutic effect of oltipraz in rats with liver cirrhosis induced by $\mathrm{N}$ dimethylnitrosamine $(3,4)$ have been reported. Oltipraz is primarily metabolized via the hepatic microsomal cytochrome P450 (CYP) 1A1/2, 2B1/2, 2C11, 2D1, and 3A1/2 (not via the CYP2E1) in male Sprague-Dawley rats (5). After intragastric administration of the drug $(75 \mathrm{mg} / \mathrm{kg} /$ day for 3 days) to male Sprague-Dawley rats, oltipraz induces activities of phase II drug metabolizing enzymes in the liver, such as glutathione Stransferase (GST) and uridine diphosphateglucuronosyl transferase (UGT), without inducing overall CYP concentrations in the liver (6). However, no induction of GST and UGT activities, and CYP contents in the small intestinal mucosa (6). Using the Northern blot analysis, it has been reported, though, that after feeding male SpragueDawley rats with the drug in $\operatorname{diet}(0.075 \%$, w/w) for 3 days, oltipraz is capable of inducing phase II detoxification enzymes, such as GST and UGT, except GSTyf, and modestly inducing CYP1A2 and 3A2 while slightly inducing CYP2B2, but not CYP2B1 (7). Based on the therapeutic effects of oltipraz in rats with liver cirrhosis $(3,4)$, oltipraz is being evaluated in phase II clinical trial in South Korea as an agent for treating patients with liver fibrosis and cirrhosis induced by chronic hepatitis types B and C.

Corresponding author: Myung G. Lee, College of Pharmacy and Research Institute of Pharmaceutical Sciences, Seoul National University, San 56-1, ShinlimDong, Kwanak-Gu, Seoul 151-742, South Korea, leemg@snu.ac.kr.

$\S$ Present Address: Department of Clinical Pharmacology, Busan Paik Hosptial, Inje University, Busan, South Korea 
Silibinin, [2,3-dihydro-3-(4-hydroxy-3-methoxyphenyl)-2-(hydroxymethyl)-6-(3,5,7-trihydroxy-4-oxobenzopyran-2-yl) benzodioxin], is a main component of the seeds of milk thistle (Silybum marianum L.). Silibinin has hepatoprotective (8) and chemopreventive (9) activities. Following intravenous $(20 \mathrm{mg} / \mathrm{kg}$ as silibinin) or oral $(2-120 \mathrm{mg} / \mathrm{kg}$ as silibinin $)$ administration of the $N$-methylglucamine salt of silibinin to rats, only $8 \%$ or $2-5 \%$ of the dose, respectively, were found in the $48 \mathrm{~h}$ urine as mostly unchanged silibinin (10). On the other hand, considerable amounts of the glucuronide and sulfate conjugates of silibinin were formed in the rats' liver and excreted via their bile. The $48 \mathrm{~h}$ biliary excretion constituted $76 \%$ and $20-35 \%$ of the dose after intravenous and oral administration, respectively, as mostly conjugates. Based on the pooled rat liver microsomes, the metabolism of silibinin was very low (11), which suggests that the metabolism of silibinin via the hepatic CYP isozymes is almost negligible in rats. Based on the rat hepatic microsomes in rats, silibinin could lead to the decrease in the glucuronidation of substrates in which conjugation depends on UGT1A isozymes in a process mediated by silibinin-glucuronide (12). Thus, the pharmacokinetic interaction between silibinin and oltipraz, especially the increase in the formation of the glucuronide and sulfate conjugates of silibinin could be expected in rats. Since both silibinin and oltipraz have hepatoprotective activities $(3,4,8)$, patients with liver disease could take both drugs. Thus, the pharmacokinetic interaction of both drugs is studied in the present study using rats as an animal model.

The purpose of this paper is to report the pharmacokinetic interaction between silibinin and oltipraz after simultaneous intravenous or oral administration of silymarin and oltipraz to male Sprague-Dawley rats.

\section{METHODS AND MATERIALS}

\section{Chemicals}

Oltipraz and DA-8164 \{5-[2-propyloxy-5(aminosulfonyl)-phenyl]-1-methyl-3- propyl- 1, 6dihydro-7H-pyrazolo- (4,3-d) pyrimidine-7-one; internal standard for the high-performance liquid chromatographic (HPLC) analysis of silibinin were donated from $\mathrm{R} \& \mathrm{D}$ Center of Pharmaceuticals, Institute of Science \& Technology,
CJ Corporation (Ichon, South Korea) and Research Laboratory of Dong-A Pharmaceutical Company, Ltd. (Yongin, South Korea), respectively. Silymarin (\#114K0756; containing 36\% of silibinin), silibinin, $\beta$-glucuronidase (Type HP-1; from Helix pomatia with a $\beta$-glucuronidase activity of 127,000 units $/ \mathrm{mL}$ and a sulfatase activity of below 7500 units $/ \mathrm{mL}$ ), and $N, N$-dimethylacetamide (DMA) were products

\section{Nonstandard abbreviations:}

HPLC, high-performance liquid chromatography; AUC, total area under the plasma concentration-time curve from time zero to time infinity; MRT, mean residence time; $\mathrm{Vd}_{\mathrm{ss}}$, apparent volume of distribution at steady state; $\mathrm{CL}$, time-averaged total body clearance; $\mathrm{CL}_{\mathrm{R}}$, time-averaged renal clearance; $\mathrm{CL}_{\mathrm{NR}}$, timeaveraged non-renal clearance; $\mathrm{Ae}_{0-24} \mathrm{~h}$, percentage of the dose excreted in the 24-h urine; $\mathrm{GI}_{24} \mathrm{~h}$, percentage of the dose recovered from the entire gastrointestinal tract (including its contents and feces) at $24 \mathrm{~h} ; C_{\max }$, maximum plasma concentration; $T_{\max }$, time to reach $C_{\max }$; $F$, extent of absolute oral bioavailability.

from Sigma-Aldrich Corporation (St. Louis, MO). Polyethylene glycol 400 (PEG 400) was purchased from Duksan Chemical Company (Seoul, South Korea). Other chemicals were of reagent or HPLC grade.

\section{Animals}

The protocols for this animal studies were approved by Animal Care and Use Committee of College of Pharmacy of Seoul National University, Seoul, South Korea. Male Sprague-Dawley rats (5-9 weeks old, weighing 215-320 g) purchased from Charles River Company Korea (Orient, Seoul, South Korea) were maintained in a clean room (Animal Center for Pharmaceutical Research, College of Pharmacy, Seoul National University) at a temperature of $20 \pm 3^{\circ} \mathrm{C}$ with $12 \mathrm{~h}$ light $(0700$ 1900) and dark (1900-0700) cycles and a relative humidity of $50 \% \pm 5 \%$. The rats were housed in metabolic cages (Tecniplast, Varese, Italy) under filtered pathogen-free air and with food (Samyang Company, Pyeongtaek, South Korea) and water available ad libitum. 


\section{Pretreatment of Rats for Intravenous and Oral Studies}

Early in the morning, the jugular vein (for drug administration in the intravenous study) and the carotid artery (for blood sampling) of each rat were cannulated with a polyethylene tube (Clay Adams, Parsippany, NJ) while each rat was under ether anesthesia (13). Both cannulae were exteriorized to the dorsal side of the neck, where each cannula was terminated with a long silastic tube (Dow Corning, Midland, MI). Both silastic tubes were inserted into a wire sheath to allow free movement of the rat. Subsequently, rats were housed individually in a metabolic cage (Daejong Scientific Company, Seoul, South Korea) and allowed to recover from the anesthesia for $4-5 \mathrm{~h}$ before beginning the experiment. Thus, the rats were not restrained during the present study.

\section{Intravenous Study}

Oltipraz [suspended $(4,5,14)$ in DMA : PEG 400 : water $=4: 4: 2, \mathrm{v} / \mathrm{v} / \mathrm{v}]$ at a dose of $10 \mathrm{mg} / \mathrm{kg}(n=$ 9), silymarin [containing $36 \%$ of silibinin (18 $\mathrm{mg}$ as silibinin); dissolved in the same media for oltipraz] at a dose of $50 \mathrm{mg} / \mathrm{kg}(n=9)$, or the drugs together $(n=8)$ was infused manually (total injection volume of $3 \mathrm{~mL} / \mathrm{kg}$ ) for $1 \mathrm{~min}$ via the jugular vein. A blood sample (approximately $0.12 \mathrm{~mL}$ for oltipraz alone, $0.22 \mathrm{~mL}$ for silymarin alone, or 0.32 $\mathrm{mL}$ for both drugs) was collected via the carotid artery at 0 (control), 1 (end of the infusion), 5, 15, $30,45,60,75,90,120,180,240,360,480$, and 600 min after the start of the intravenous infusion of the drug(s). A blood sample (approximately $1.5 \mathrm{~mL}$ ) collected from the untreated rats was infused via the carotid artery at $120 \mathrm{~min}$ (for oltipraz alone), 120 and $180 \mathrm{~min}$ (for silibinin alone), or 120, 180, and $240 \mathrm{~min}$ (for both drugs), respectively, after the blood sampling to replace the lost blood due to the blood sampling. A blood sample was immediately centrifuged and a $50 \mu \mathrm{L}$ of plasma sample was stored at $-70^{\circ} \mathrm{C}$ (Revco ULT $1490 \mathrm{D}-\mathrm{N}-\mathrm{S}$; Western Mednics, Ashville, NC) until analyzed for oltipraz and unconjugated and conjugated (sulfate and glucuronide) silibinin using HPLC. Analysis of each drug required a $50 \mu \mathrm{L}$ of plasma. At the end of the experiment $(24 \mathrm{~h})$, each metabolic cage was rinsed with $15 \mathrm{~mL}$ of distilled water which was combined with the $24 \mathrm{~h}$ urine sample. After the exact volume of the combined urine samples was measured, a $50-\mu \mathrm{L}$ (for oltipraz alone), two $50 \mu \mathrm{L}$ (for silymarin alone), or three $50 \mu \mathrm{L}$ (for the drugs together) aliquots of the combined urine sample was stored at $-70^{\circ} \mathrm{C}$ until used for the HPLC analysis of oltipraz and unconjugated and conjugated silibinin. At $24 \mathrm{~h}$, as much blood as possible was collected via the carotid artery before rats were sacrificed by cervical dislocation. Then the abdomen was opened and the entire gastrointestinal tract (including its contents and feces) of each rat was removed, transferred into a beaker containing $100 \mathrm{~mL}$ of methanol (to facilitate the extraction of oltipraz and silibinin), and cut into small pieces with scissors. After stirring with a glass rod for $1 \mathrm{~min}$, a $50 \mu \mathrm{L}$ (for oltipraz alone), two $50 \mu \mathrm{L}$ (for silymarin alone), or three $50 \mu \mathrm{L}$ (for the drugs together) aliquots of the supernatant were collected from each beaker and stored at $-70^{\circ} \mathrm{C}$ until used for the HPLC analysis of oltipraz and unconjugated and conjugated silibinin.

\section{Oral Study}

Oltipraz (the same suspension used in the intravenous study) at a dose of $30 \mathrm{mg} / \mathrm{kg}(n=8)$, silymarin (the same solution used in the intravenous study) at a dose of $100 \mathrm{mg} / \mathrm{kg}$ (36 $\mathrm{mg} / \mathrm{kg}$ as silibinin) $(n=12)$, or the drugs together $(n=8)$ was administered orally (total oral volume of $3 \mathrm{~mL} / \mathrm{kg}$ ) using a gastric gavage. Similar experiments were also performed after daily oral administration of the same dose of silymarin for 14 days. Then the same dose of oltipraz $(n=12)$, silymarin $(n=8)$, or the drugs together $(n=10)$ was orally administered on the 15 th day. A blood sample was collected right after the start of the oral administration of the drug(s) on the 15th day. The blood sampling time schedules were $0,15,30,60$, $90,120,180,240,360,480,600,720,960,1200$, and $1440 \mathrm{~min}$ after the oral administration of the drug(s). Freshly collected blood from untreated rats were injected to replace the lost volume. Other procedures were similar to those for the intravenous administration. Silymarin at a dose of $100 \mathrm{mg} / \mathrm{kg}$ $(36 \mathrm{mg} / \mathrm{kg}$ as silibinin) was orally administered using a gastric gavage to ten rats after bile duct cannulation (14), and the bile (between $0-1,1-2$, 2-4, 4-6, 6-12, and 12-24 h) and blood samples were collected. Other procedures were similar to those for the oral study. 


\section{Measurement of Rat Plasma Protein Binding of Oltipraz and Silibinin Using Equilibrium Dialysis}

Protein binding of oltipraz (at a concentration of 5 $\mu \mathrm{g} / \mathrm{mL}$ ) and silibinin (at a concentration of 20 $\mu \mathrm{g} / \mathrm{mL}$ ) in the presence or absence of each other to fresh plasma from the control rats was measured using equilibrium dialysis (15). Plasma (1 mL) from the control rats $(n=5)$ was dialyzed against 1 $\mathrm{mL}$ of isotonic Sørensen phosphate buffer $(\mathrm{pH} 7.4)$ containing $3 \%(\mathrm{w} / \mathrm{v})$ dextran ('the buffer') to reduce the volume shift (16) in a $1 \mathrm{~mL}$ dialysis cell (Spectrum Medical Industries, Los Angeles, CA) using a Spectra/Por 4 membrane (mol. wt. cutoff 12-14 kDa; Spectrum Medical Industries). To reduce the equilibrium time between the plasma and 'the buffer' compartments, each drug was spiked into the plasma side (17). After $24 \mathrm{~h}$ incubation, two $100 \mu \mathrm{L}$ aliquots were collected from each compartment and stored at $-70^{\circ} \mathrm{C}$ until used for the HPLC analysis of oltipraz and silibinin.

\section{HPLC Analysis of Oltipraz and Silibinin}

Concentrations of oltipraz in the samples were determined using a reported HPLC method (18). In brief, a $100 \mu \mathrm{L}$ of acetonitrile was added to deproteinize a $50 \mu \mathrm{L}$ of the biological sample. After vortex-mixing and centrifugation $(16,000 \mathrm{~g}, 1 \mathrm{~min})$, a $50 \mu \mathrm{L}$ of the supernatant was directly injected onto the reversed phase $\left(\mathrm{C}_{18} ; 250 \mathrm{~mm}, \ell . \times 4.6 \mathrm{~mm}\right.$, i.d.; particle size, $10 \mu \mathrm{m}$; Hibar, Merck KGaA, Darmstadt, Germany) HPLC column. The mobile phase, acetonitrile : $0.5 \mathrm{mM}$ ammonium acetate (55:45, v/v, for the rat plasma, and $45: 55, \mathrm{v} / \mathrm{v}$, for the rat urine samples), was run at a flow rate of 1.5 $\mathrm{mL} / \mathrm{min}$, and the column eluent was monitored using an ultraviolet detector at $305 \mathrm{~nm}$ at room temperature. The retention times of oltipraz were 5.8 and $8.6 \mathrm{~min}$ in the rat plasma and urine samples, respectively. The minimum quantifiable concentrations of oltipraz in the rat plasma and urine samples were 20 and $50 \mathrm{ng} / \mathrm{mL}$, respectively. The mean intra-day coefficients of variations (C.V.) in the rat plasma and urine samples were $2.29 \%$ and $1.01 \%$, respectively, and the corresponding interday C.V. values of the analysis of the same samples on three consecutive days were $3.37 \%$ and $1.51 \%$, respectively. Since oltipraz in a solution has been reported to induce photodegradation (19), all the samples for oltipraz in this present study were covered (or wrapped) with aluminum foil during the experiment or kept in the dark when they were not in use.

Concentrations of unconjugated and total silibinin (unconjugated plus conjugated) in the samples were determined using a modification of a reported HPLC method (20); the Nucleosil 100-5 CN column was changed to the reversed phase HPLC column, the mobile phase was changed from acetonitrile : $0.2 \mathrm{M}$ acetic acid $(20: 80, \mathrm{v} / \mathrm{v})$ to acetonitrile : $1 \mathrm{mM}$ ammonium acetate $33: 67$, $\mathrm{v} / \mathrm{v})$, and DA-8164 was used as an internal standard. To analyze unconjugated silibinin, a $50 \mu \mathrm{L}$ of methanol containing a $10 \mu \mathrm{g} / \mathrm{mL}$ of DA-8164 (internal standard), a $100 \mu \mathrm{L}$ of $0.5 \mathrm{M}$ borate buffer (pH 8.5), and $1 \mathrm{~mL}$ of ethylether were added to a 50 $\mu \mathrm{L}$ of the sample. After vortex-mixing for $1 \mathrm{~min}$, the mixture was centrifuged $(10,000 \mathrm{~g}, 5 \mathrm{~min})$, after which the organic layer was collected and dried under a gentle stream of nitrogen gas at $40^{\circ} \mathrm{C}$. The residue was reconstituted in a $100 \mu \mathrm{L}$ of the mobile phase, vortexed for $30 \mathrm{~s}$, and centrifuged $(10,000 \mathrm{~g}$, $1 \mathrm{~min}$ ). Then a $50 \mu \mathrm{L}$ of the supernatant was injected directly onto a reversed phase HPLC column at room temperature. To analyze total silibinin, a $50 \mu \mathrm{L}$ of $0.1 \mathrm{M}$ acetate buffer ( $\mathrm{pH}$ 5.6) and a $30 \mu \mathrm{L}$ of $\beta$-glucuronidase (3810 and 225 units $/ \mathrm{mL}$ for $\beta$-glucuronidase and sulfatase activities, respectively) were added to a $50 \mu \mathrm{L}$ of the sample, after which the mixtures were incubated for $3 \mathrm{~h}$ in a thermomixer [Thermomixer 5436; Eppendorf, Hamburg, Germany; $37^{\circ} \mathrm{C}, 600$ revolutions per $\min (\mathrm{rpm})]$. Other procedures were the same as those for unconjugated silibinin. In the preliminary study, the plasma concentrations of total silibinin 1, 5, 30, and $60 \mathrm{~min}$ after the intravenous administration of silymarin were constant after their incubation with 30 to $70 \mu \mathrm{L}$ aliquots of $\beta$-glucuronidase. Thus, a $30 \mu \mathrm{L}$ of $\beta$ glucuronidase was used in this study. Concentrations of conjugated silibinin were determined by subtracting the unconjugated silibinin concentration from the total (conjugated plus unconjugated) silibinin concentration (after incubation with $\beta$-glucuronidase). The mobile phase, acetonitrile : $1 \mathrm{mM}$ ammonium acetate (33 : $67, \mathrm{v} / \mathrm{v}$, for the rat plasma, and $30: 70, \mathrm{v} / \mathrm{v}$, for the rat urine samples), was run at a flow rate of 1.5 $\mathrm{mL} / \mathrm{min}$, and the column eluent was monitored 
using an ultraviolet detector at $305 \mathrm{~nm}$ at room temperature. The retention times of silibinin and DA-8164 (internal standard) were 5.2 and $11.7 \mathrm{~min}$, respectively, in the rat plasma samples, and 7.5 and $18.5 \mathrm{~min}$, respectively, in the rat urine samples. The minimum quantifiable concentrations of silibinin in the rat plasma and urine samples were 30 and 100 $\mathrm{ng} / \mathrm{mL}$, respectively. The mean intra-day C.V. values in the rat plasma and urine samples were $8.39 \%$ and $4.42 \%$, respectively, and the corresponding values for the inter-day C.V. of the analysis of the same samples on three consecutive days were $8.87 \%$ and $4.72 \%$, respectively.

\section{Pharmacokinetic Analysis}

The total area under the plasma concentration-time curve from time zero to time infinity (AUC) or up to the last measured time, $12 \mathrm{~h}\left(\mathrm{AUC}_{0-12 \mathrm{~h}}\right)$, in the plasma were calculated using the trapezoidal ruleextrapolation method (21). The area from the last datum point to time infinity (for the calculation of the AUC) was calculated by dividing the last measured plasma concentration by the terminal phase rate constant.

Standard methods (22) were used to calculate the following pharmacokinetic parameters using a noncompartmental analysis (WinNonlin ${ }^{\circledR}$; Pharsight Corporation, Mountain View, CA); the timeaveraged total body, renal, and nonrenal clearances (CL, $\mathrm{CL}_{\mathrm{R}}$, and $\mathrm{CL}_{\mathrm{NR}}$, respectively), the terminal half life, the first moment of the AUC (AUMC), the mean residence time (MRT), the apparent volume of distribution at a steady state $\left(\mathrm{Vd}_{\mathrm{ss}}\right)$, and the extent of absolute oral bioavailability $(F)(13)$. The peak plasma concentration $\left(C_{\max }\right)$ and time to reach $C_{\max }\left(T_{\max }\right)$ were directly read from the experimental data.

\section{Statistical Analysis}

A $p$ value $<0.05$ was deemed to be statistically significant using an unpaired Student's $t$-test. All the results were expressed as means \pm standard deviations, except the medians (ranges) for $T_{\max }$.

\section{RESULTS}

\section{Pharmacokinetics of Intravenous Oltipraz}

Figure 1A depicts the mean arterial plasma concentration-time profiles of oltipraz after its intravenous administration to the rats with or without simultaneous intravenous administration of silymarin. The relevant pharmacokinetic parameters are listed in Table 1. The pharmacokinetic parameters of oltipraz were not significantly influenced by the presence of silymarin except for the MRT that was significantly shorter by $25.1 \%$ decrease. The percentages of the intravenous dose of oltipraz excreted in the $24 \mathrm{~h}$ urine as unchanged drug $\left(\mathrm{Ae}_{0-24 \mathrm{~h}}\right)$ were below the detection limit for both groups of rats, which suggests that almost the entire intravenously administered oltipraz is eliminated via the nonrenal route $\left(\mathrm{CL}_{\mathrm{NR}}\right)$ for both groups of rats. It has been reported that oltipraz is metabolized into 13 metabolites in rats (23). In this study, oltipraz was also below the detection limit in the gastrointestinal tract (including its contents and feces) at $24 \mathrm{~h}\left(\mathrm{GI}_{24 \mathrm{~h}}\right)$.

\section{Pharmacokinetics of Unconjugated, Conjugated, and Total Silibinin after Intravenous Administration of Silymarin}

Figures 1B-1D depict the mean arterial plasma concentration-time profiles of unconjugated, conjugated, and total silibinin, respectively, after intravenous administration of $50 \mathrm{mg} / \mathrm{kg}$ silymarin $(18 \mathrm{mg} / \mathrm{kg}$ as silibinin) with or without simultaneous intravenous administration of oltipraz. The relevant pharmacokinetic parameters are listed in Table 2. With oltipraz, the AUC of the unconjugated silibinin was significantly smaller (32.7\% decrease) while the AUC values of both the conjugated and total (unchanged plus conjugated) silibinin were significantly greater $(32.1 \%$ and $27.2 \%$ increase, respectively). With oltipraz, the CL and $\mathrm{CL}_{\mathrm{NR}}$ of the unconjugated silibinin were significantly faster $(49.4 \%$ and $61.1 \%$ increase, respectively) and the $\mathrm{Vd}_{\mathrm{ss}}$ of the unconjugated silibinin was significantly larger (131\% increase). The unconjugated silibinin was below the detection limit in the $\mathrm{GI}_{24} \mathrm{~h}$ for both groups of rats, but the values of the total silibinin were $0.724 \%$ and $0.617 \%$ of the intravenous dose of silibinin for with and without oltipraz, respectively. Since the 
unconjugated silibinin was below the detection limit for both groups of rats, the $\mathrm{GI}_{24} \mathrm{~h}$ values of the conjugated silibinin could be similar to the values of the total silibinin.

\section{Pharmacokinetics of Oral Oltipraz}

Figure 2A depicts the mean arterial plasma concentration-time profiles of oltipraz after its oral administration to the rats with or without simultaneous oral administration of silymarin. The relevant pharmacokinetic parameters are listed in Table 3. After single oral administration of oltipraz to both with and without $100 \mathrm{mg} / \mathrm{kg}$ silymarin (36 $\mathrm{mg} / \mathrm{kg}$ silibinin), absorption of oltipraz was rapid (Figure 2A, Table 3); oltipraz was detected in the plasma from the first sampling time $(15 \mathrm{~min})$ for both groups of rats. However, the absorption patterns of oltipraz differed between the two groups of rats. For example, without silymarin, the plasma concentrations of oltipraz kept increasing up to the peak $\left(T_{\max }\right)$ at $600 \mathrm{~min}$, and then decreased thereafter in a monoexponential fashion. With silymarin, however, the plasma concentrations of oltipraz reached the peak $\left(T_{\max }\right)$ at $97.5 \mathrm{~min}$ and then decreased thereafter. The abovementioned data suggest that silymarin enhanced the rate, but not the extent, of oltipraz absorption. The pharmacokinetic parameters of oltipraz listed in Table 3 did not differ significantly between the two groups of rats, except that there was a significantly shorter $T_{\max }$ $(83.8 \%$ decrease) with silymarin.
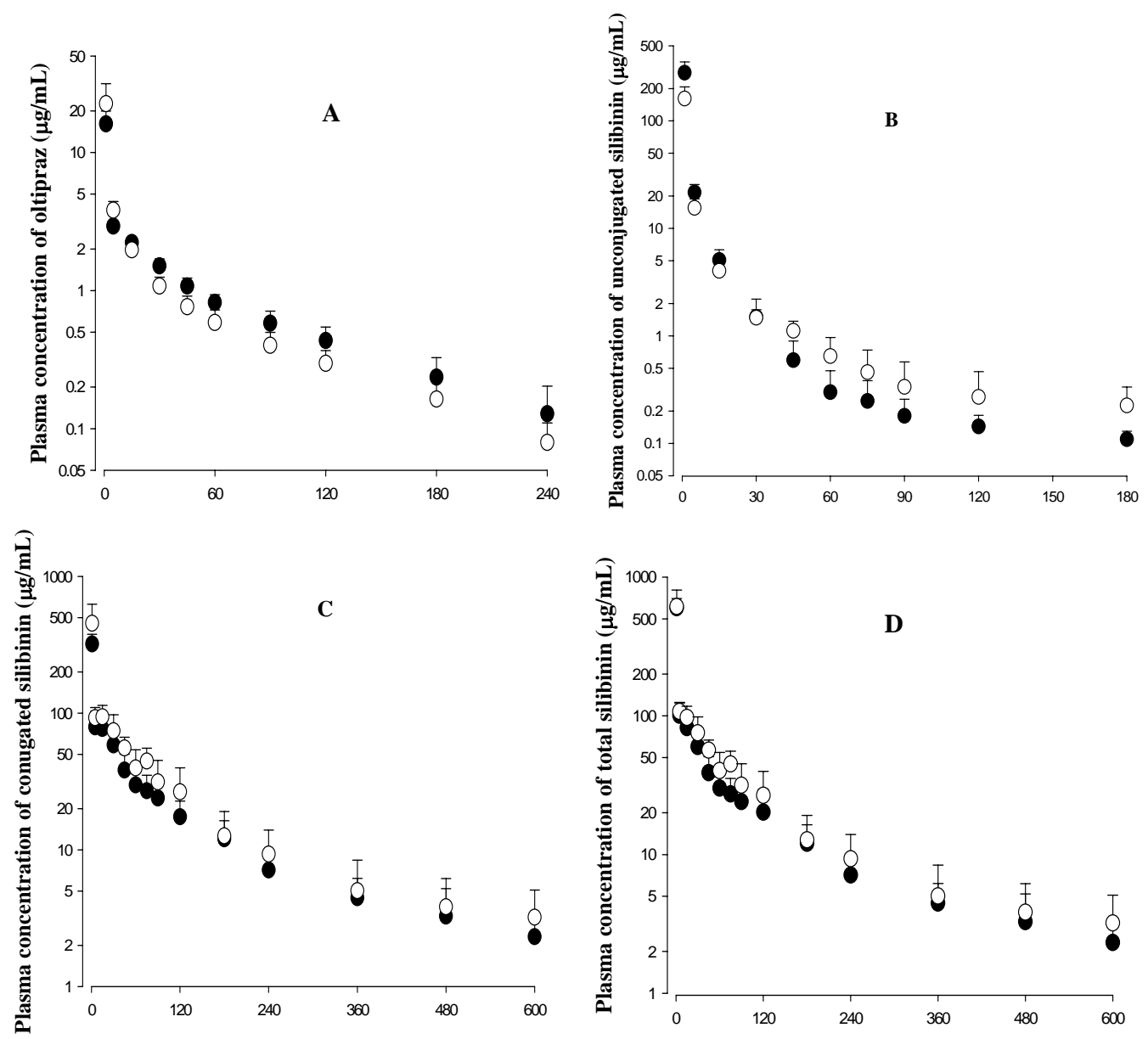

Figure 1: Mean arterial plasma concentration-time profiles of oltipraz (A) after intravenous administration of oltipraz at a dose of $10 \mathrm{mg} / \mathrm{kg}$ without $(\bullet ; n=9)$ or with $(\circ ; n=8)$ simultaneous intravenous administration of silymarin at a dose of 50 $\mathrm{mg} / \mathrm{kg}$, and of unconjugated (B), conjugated (C), and total (D) silibinin after intravenous administration of silymarin at a dose of $50 \mathrm{mg} / \mathrm{kg}$ with $(\circ ; n=8)$ or without $(\bullet ; n=9)$ simultaneous intravenous administration of oltipraz at a dose of 10 $\mathrm{mg} / \mathrm{kg}$ to rats. Bars represent standard deviations. 
Pharmacokinetics of Unconjugated, Conjugated, and Total Silibinin after Oral Administration of Silymarin

Figures 2B-2D depict the mean arterial plasma concentration-time profiles of unconjugated, conjugated, and total silibinin, respectively, after single oral administration of silymarin to the rats with or without simultaneous oral administration of oltipraz. The relevant pharmacokinetic parameters are listed in Table 4. After single oral administration of silymarin with or without oltipraz, absorption of silymarin was also rapid; unconjugated silibinin was detected in the plasma from the first sampling time $(15 \mathrm{~min})$ and reached time $\left(15 \mathrm{~min}\right.$ ) and reached $\mathrm{C}_{\max }$ at $15 \mathrm{~min}$ for both groups of rats, the plasma concentration of unconjugated silibinin decreased up to $90 \mathrm{~min}$, and then fluctuated thereafter up to $720 \mathrm{~min}$. The pharmacokinetic parameters of unconjugated, conjugated, and total silibinin listed in Table 4 did not differ significantly between the two groups of rats. Note that multiple peaks in the plasma concentrations of unconjugated silibinin were observed for both groups of rats, and a similar pattern could be also shown for both conjugated and total silibinin.

\section{Pharmacokinetics of Oltipraz after Oral Administration of Silymarin for 14 Days}

Figure 3A depicts the mean arterial plasma concentration-time profiles of oltipraz after oral administration of oltipraz to the rats with or without simultaneous oral administration of silymarin for 14 days. The relevant pharmacokinetic parameters are listed in Table 5. After oral administration of oltipraz with or without silymarin, absorption of oltipraz was again rapid; oltipraz was detected in the plasma from the first sampling time $(15 \mathrm{~min})$ for both groups of rats. The pharmacokinetic parameters of oltipraz listed in Table 5 did not differ significantly between the two groups of rats.
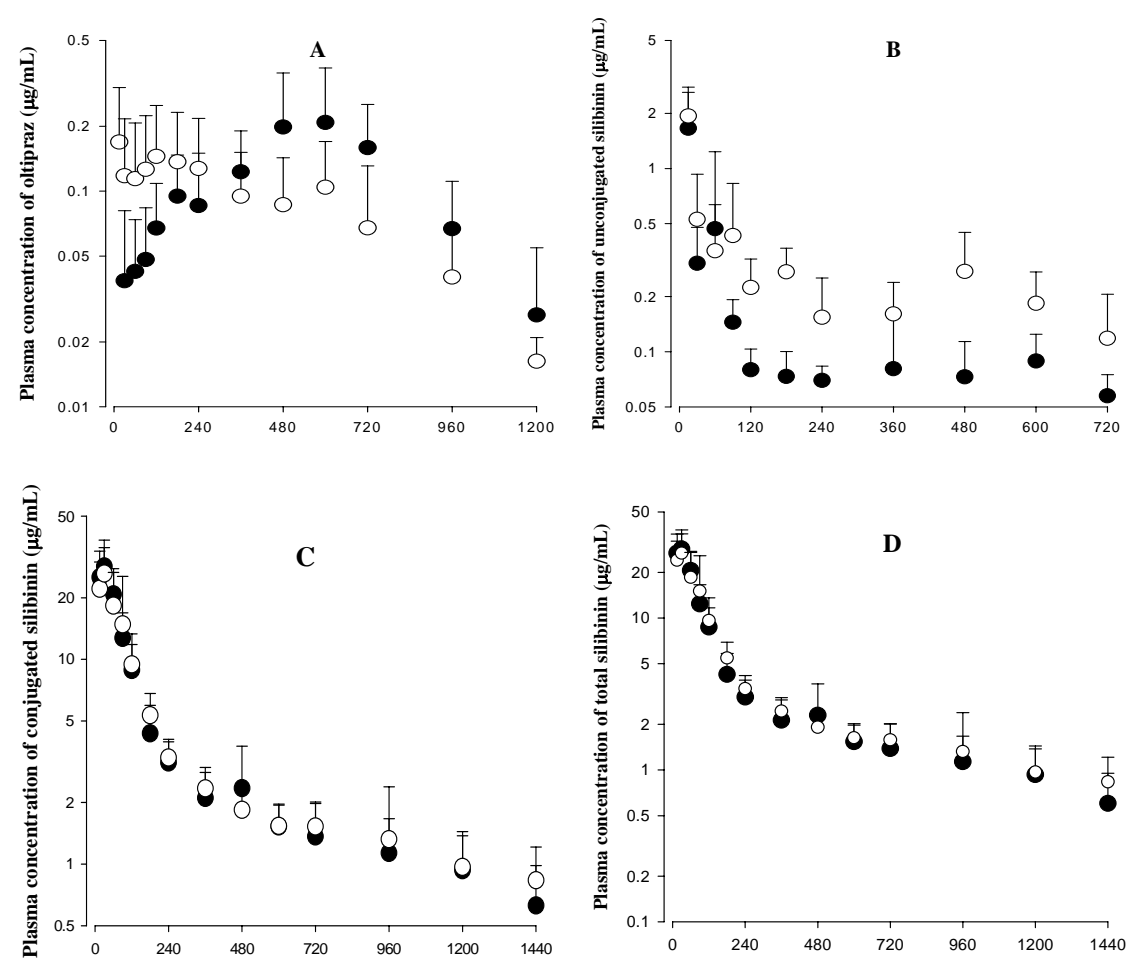

Figure 2: Mean arterial plasma concentration-time profiles of oltipraz (A) after oral administration of oltipraz at a dose of $30 \mathrm{mg} / \mathrm{kg}$ with $(\circ ; n=8)$ or without $(\bullet ; n=8)$ simultaneous oral administration of silymarin at a dose of $100 \mathrm{mg} / \mathrm{kg}$, and of unconjugated (B), conjugated (C), and total (D) silibinin after oral administration of silymarin at a dose of $100 \mathrm{mg} / \mathrm{kg}$ with $(\circ ; n=8)$ or without $(\bullet ; n=12)$ simultaneous oral administration of oltipraz at a dose of $30 \mathrm{mg} / \mathrm{kg}$ to rats. Bars represent standard deviations. 
Table 1: Mean ( \pm standard deviation) pharmacokinetic parameters of oltipraz after intravenous infusion of oltipraz at a dose of $10 \mathrm{mg} / \mathrm{kg}$ with or without simultaneous intravenous infusion of silymarin at a dose of $50 \mathrm{mg} / \mathrm{kg}$ to rats.

\begin{tabular}{|c|c|c|c|c|c|}
\hline \multirow{2}{*}{$\begin{array}{l}\text { Parameter } \\
\text { AUC }(\mu \mathrm{g} * \mathrm{~min} / \mathrm{mL})\end{array}$} & \multicolumn{2}{|c|}{$\begin{array}{l}\text { Without silymarin } \\
\quad(n=9)\end{array}$} & \multicolumn{3}{|c|}{$\begin{array}{l}\text { With silymarin } \\
\quad(n=8)\end{array}$} \\
\hline & 206 & $\pm \quad 36.1$ & 179 & \pm & 28.9 \\
\hline Terminal half life (min) & 67.9 & $\pm \quad 16.3$ & 62.1 & \pm & 9.99 \\
\hline $\operatorname{MRT}(\min )$ & 72.4 & $\pm \quad 18.8$ & 54.2 & \pm & $10.8^{\mathrm{a}}$ \\
\hline $\mathrm{Vd}_{\mathrm{ss}}(\mathrm{mL} / \mathrm{kg})$ & 3500 & $\pm \quad 479$ & 3090 & \pm & 750 \\
\hline $\mathrm{CL}(\mathrm{mL} / \mathrm{min} / \mathrm{kg})$ & 49.8 & $\pm \quad 7.87$ & 57.2 & \pm & 10.0 \\
\hline $\mathrm{CL}_{\mathrm{R}}(\mathrm{mL} / \mathrm{min} / \mathrm{kg})$ & \multicolumn{2}{|r|}{$\mathrm{BD}^{\mathrm{b}}$} & \multicolumn{3}{|c|}{$\mathrm{BD}$} \\
\hline $\mathrm{CL}_{\mathrm{NR}}(\mathrm{mL} / \mathrm{min} / \mathrm{kg})$ & 49.8 & $\pm \quad 7.87$ & 57.2 & \pm & 10.0 \\
\hline $\mathrm{Ae}_{0-24 \mathrm{~h}}(\%$ of the oltiprz dose $)$ & \multicolumn{2}{|r|}{$\mathrm{BD}$} & \multicolumn{3}{|c|}{$\mathrm{BD}$} \\
\hline $\mathrm{GI}_{24 \mathrm{~h}}$ (\% of the oltipraz dose) & \multicolumn{2}{|r|}{$\mathrm{BD}$} & \multicolumn{3}{|c|}{$\mathrm{BD}$} \\
\hline
\end{tabular}

${ }^{a}$ Significantly different $(\mathrm{p}<0.05)$ from without silymarin; BD, below the detection limit.
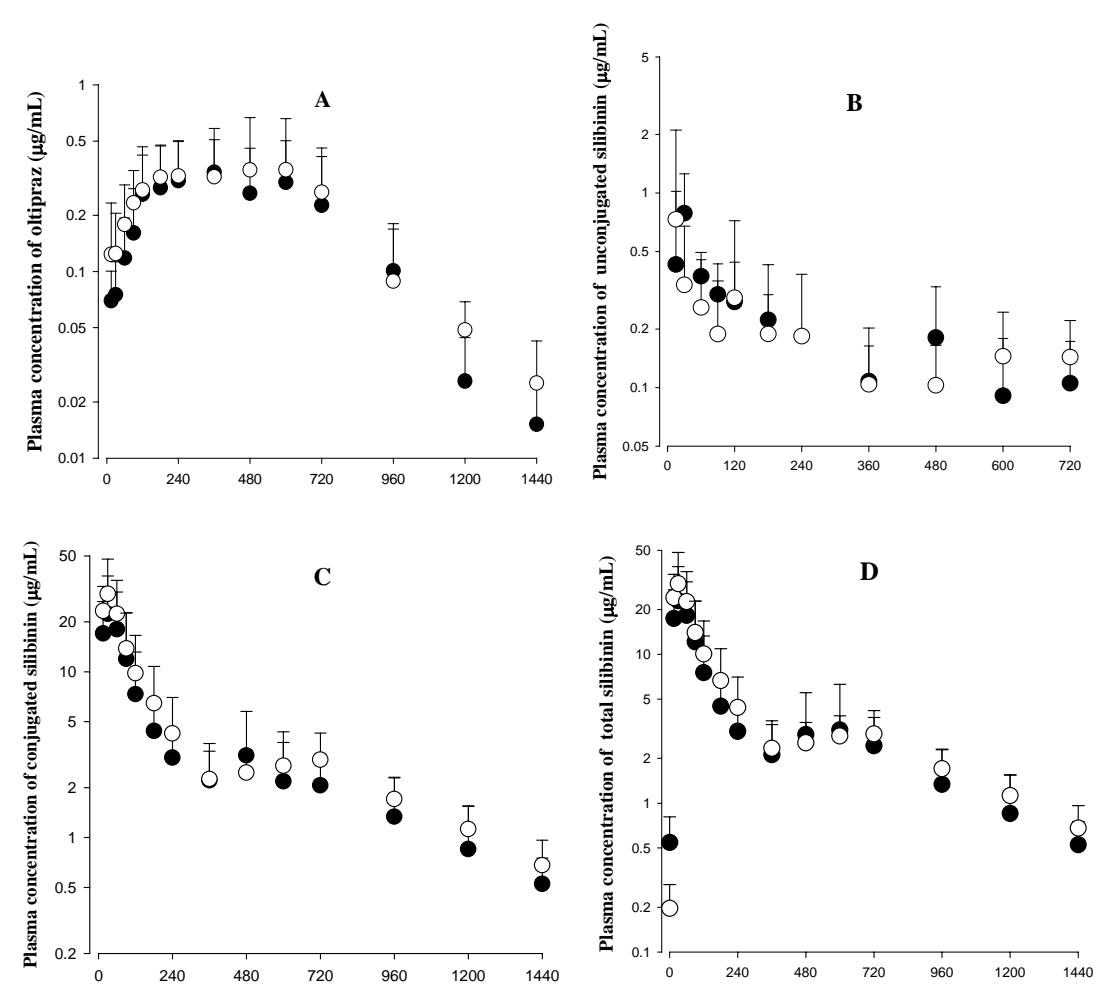

Figure 3: Mean arterial plasma concentration-time profiles of oltipraz (A) after oral administration of oltipraz at a dose of $30 \mathrm{mg} / \mathrm{kg}$ with $(\circ ; n=10)$ or without $(\bullet ; n=12)$ simultaneous oral administration of silymarin at a dose of $100 \mathrm{mg} / \mathrm{kg}$, and of unconjugated (B), conjugated (C), and total (D) silibinin after oral administration of silymarin at a dose of $100 \mathrm{mg} / \mathrm{kg}$ with $(\circ ; n=10)$ or without $(\bullet ; n=8)$ simultaneous oral administration of oltipraz at a dose of $30 \mathrm{mg} / \mathrm{kg}$ with daily oral administration of silymarin at a dose $100 \mathrm{mg} / \mathrm{kg} /$ day for 14 days. Bars represent standard deviations. 
Table 2: Mean ( \pm standard deviation) pharmacokinetic parameters of unconjugated, conjugated, and total silibinin after intravenous infusion of silymarin at a dose of 50 $\mathrm{mg} / \mathrm{kg}$ with or without simultaneous intravenous infusion of oltipraz at a dose of $10 \mathrm{mg} / \mathrm{kg}$ to rats.

\begin{tabular}{|c|c|c|c|c|c|c|c|c|c|c|c|c|c|c|c|c|}
\hline \multirow{3}{*}{$\begin{array}{l}\text { Parameter } \\
\text { AUC }(\mu \mathrm{g} * \min / \mathrm{mL})\end{array}$} & \multicolumn{9}{|c|}{ Without oltipraz $(n=9)$} & \multicolumn{7}{|c|}{ With oltipraz $(n=8)$} \\
\hline & \multicolumn{3}{|c|}{ Unconjugated } & \multicolumn{3}{|c|}{ Conjugated } & \multicolumn{3}{|c|}{ Total } & Unconjugated & \multicolumn{3}{|c|}{ Conjugated } & \multicolumn{3}{|c|}{ Total } \\
\hline & 740 & \pm & 143 & 8860 & \pm & 1520 & 9670 & \pm & 1630 & $498 \pm 105^{\mathrm{a}}$ & 11700 & \pm & $3310^{\mathrm{b}}$ & 12300 & \pm & $3210^{\mathrm{b}}$ \\
\hline Terminal half life (min) & 48.5 & \pm & 24.9 & 185 & \pm & 67.0 & 200 & \pm & 73.4 & $46.8 \pm 23.4$ & 156 & \pm & 43.1 & 203 & \pm & 49.4 \\
\hline MRT (min) & 8.99 & \pm & 3.14 & & nd & & & nd & & $15.5 \pm 10.6$ & & nd & & & nd & \\
\hline $\mathrm{Vd}_{\mathrm{ss}}(\mathrm{mL} / \mathrm{kg})$ & 229 & \pm & 98.2 & & nd & & & nd & & $533 \pm 281^{\mathrm{b}}$ & & nd & & & nd & \\
\hline $\mathrm{CL}(\mathrm{mL} / \mathrm{min} / \mathrm{kg})$ & 25.3 & \pm & 5.57 & & nd & & & nd & & $37.6 \pm 7.99^{\mathrm{b}}$ & & nd & & & nd & \\
\hline $\mathrm{CL}_{\mathrm{R}}(\mathrm{mL} / \mathrm{min} / \mathrm{kg})$ & 0.904 & \pm & 0.881 & & nd & & & nd & & $0.286 \pm 0.178$ & & nd & & & nd & \\
\hline $\mathrm{CL}_{\mathrm{NR}}(\mathrm{mL} / \mathrm{min} / \mathrm{kg})$ & 24.6 & \pm & 5.36 & & nd & & & nd & & $37.5 \pm 7.92^{\mathrm{b}}$ & & nd & & & nd & \\
\hline $\begin{array}{l}\mathrm{Ae}_{0-24 \mathrm{~h}} \\
(\% \text { of the silibinin dose) }\end{array}$ & 3.41 & \pm & 3.28 & 2.33 & \pm & 2.19 & 3.98 & \pm & 2.54 & $0.722 \pm 0.415$ & 0.391 & \pm & 0.0887 & 1.50 & \pm & 1.66 \\
\hline $\mathrm{GI}_{24 \mathrm{~h}}(\%$ of the silibinin dose $)$ & & & $3 \mathrm{D}^{\mathrm{c}}$ & & & & 0.764 & \pm & 0.294 & $\mathrm{BD}$ & & & & 0.651 & \pm & 0.201 \\
\hline
\end{tabular}


Table 3: Mean ( \pm standard deviation) pharmacokinetic parameters of oltipraz after oral administration of oltipraz at a dose of $30 \mathrm{mg} / \mathrm{kg}$ with or without simultaneous oral administration of silymarin at a dose of 100 $\mathrm{mg} / \mathrm{kg}$ to rats.

\begin{tabular}{lcc}
\hline Parameter & $\begin{array}{c}\text { Without silymarin } \\
(\boldsymbol{n}=\mathbf{8})\end{array}$ & $\begin{array}{c}\text { With silymarin } \\
(\boldsymbol{n}=\mathbf{8})\end{array}$ \\
\hline $\mathrm{AUC}(\mu \mathrm{g} * \mathrm{~min} / \mathrm{mL})$ & $143 \pm 79.3$ & $111 \pm 58.0$ \\
Terminal half life $(\mathrm{min})$ & $237 \pm 118$ & $245 \pm 126$ \\
$T_{\max }(\mathrm{min})$ & $600(120-720)$ & $97.5(15-600)^{\mathrm{a}}$ \\
$C_{\max }(\mu \mathrm{g} / \mathrm{mL})$ & $0.256 \pm 0.152$ & $0.185 \pm 0.112$ \\
$\mathrm{CL}_{\mathrm{R}}(\mathrm{mL} / \mathrm{min} / \mathrm{kg})$ & $0.0204 \pm 0.00768$ & $0.133 \pm 0.102$ \\
$\mathrm{Ae}_{0-24 \mathrm{~h}}(\%$ of the oral dose $)$ & $0.00910 \pm 0.00249$ & $0.0467 \pm 0.0540$ \\
$\mathrm{GI}_{24 \mathrm{~h}}(\%$ of the oral dose $)$ & $15.4 \pm 19.5$ & $4.80 \pm 4.87$ \\
$F(\%)$ & 23.1 & 20.7 \\
\hline
\end{tabular}

${ }^{\mathrm{a}}$ Significantly different $(\mathrm{p}<0.01)$ from without silymarin.

Pharmacokinetics of Unconjugated, Conjugated, and Total Oral Silibinin after Oral Administration of Silymarin for 14 Days

Figures 3B-3D depict the mean arterial plasma concentration-time profiles of unconjugated, conjugated, and total silibinin, respectively, after oral administration of silymarin for 14 days to rats with or without simultaneous oral administration of oltipraz. The relevant pharmacokinetic parameters are listed in Table 6. After oral administration of silymarin with or without oltipraz, absorption of silymarin was again rapid; unconjugated silibinin was detected in the plasma from the first blood sampling time $(15 \mathrm{~min})$ for both groups of rats. The pharmacokinetic parameters of unconjugated, conjugated, and total silibinin listed in Table 6 did not differ significantly between the two groups of rats. Note that the multiple peaks in the plasma concentration of unconjugated, conjugated, and total silibinin were also observed for both groups of rats.

Pharmacokinetics of Unconjugated, Conjugated, and Total Silibinin after Oral Administration of Silymarin with Bile Duct Cannulation

Figure 4 depicts the mean arterial plasma concentration-time curves of unconjugated and total silibinin after oral administration of silymarin to rats with bile duct cannulation. The relevant pharmacokinetic parameters are listed in Table 7. The unconjugated silibinin was below the detection limit in the plasma from the $90 \mathrm{~min}$ blood sampling time. The multiple peak phenomenon of total silibinin was also observed. The $24 \mathrm{~h}$ biliary excretions of unconjugated, conjugated, and total silibinin were $0.261 \% \pm 0.381 \%, 22.2 \% \pm 10.4 \%$, and $22.5 \% \pm 10.6 \%$ of the oral dose of silibinin, respectively, with bile duct cannulation (Figure 5).

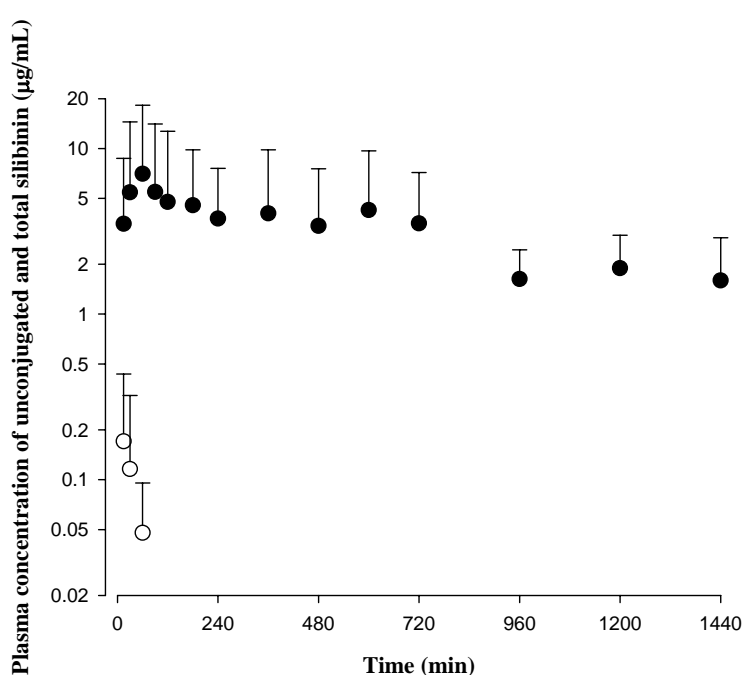

Figure 4: Mean arterial plasma concentration-time profiles of unconjugated $(\circ)$ and total $(\bullet)$ silibinin after oral administration of silymarin at a dose of $100 \mathrm{mg} / \mathrm{kg}$ to rats with bile duct cannulation. Bars represent standard deviations.

\section{Rat Plasma Protein Binding of Oltipraz and Silibinin}

Protein binding values of oltipraz to the fresh 
plasma from the control rats were $87.3 \pm 2.76 \%$ and $83.3 \pm 2.96 \%$ for with and without silibinin, respectively; they were not significantly different. The values of silibinin were $96.1 \pm 1.34 \%$ and 95.7 $\pm 2.20 \%$ for with and without oltipraz, respectively; they were also not significantly different.

\section{DISCUSSION}

After simultaneous intravenous (Table 1) or oral (Tables 3 and 5) administration of oltipraz with silymarin, the pharmacokinetic parameters of oltipraz did not differ significantly compared to those of without silymarin, which suggests that silymarin (silibinin) has no effect on the pharmacokinetics of oltipraz in the rats. Although oltipraz was reported to be metabolized via the hepatic CYP1A1/2, 2B1/2, 2C11, 2D1, and 3A1/2 in the rats (5), silibinin might not have any effect on hepatic CYP isozymes. Based on primary cultures

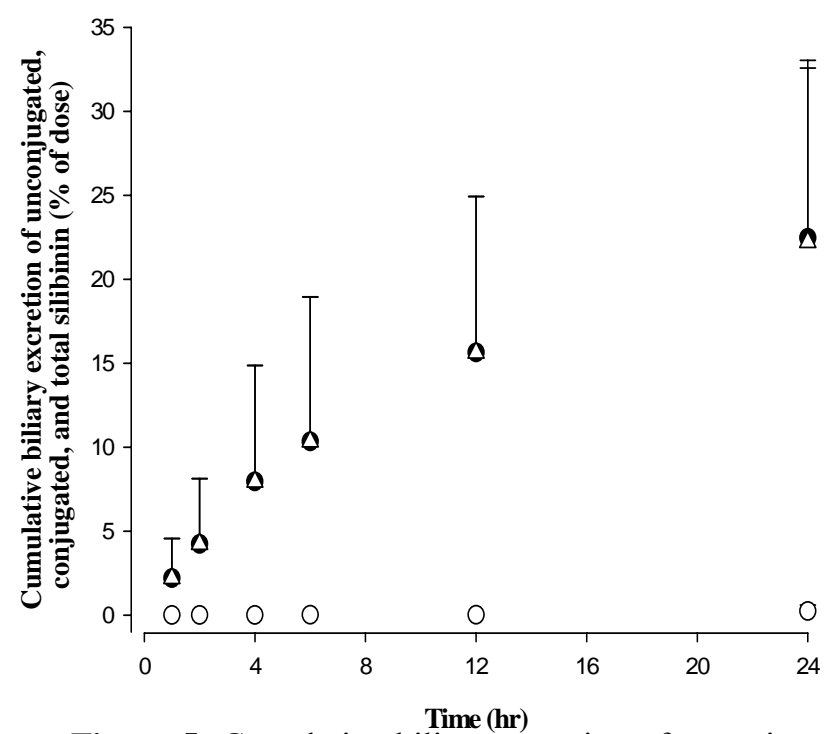

Figure 5: Cumulative biliary excretion of unconjugated $(\circ)$, conjugated () , and total $(\bullet)$ silibinin after oral administration of silymarin at a dose of $100 \mathrm{mg} / \mathrm{kg}$ to rats with bile duct cannulation. Bars represent standard deviations.

of human hepatocytes, silibinin did not induce the expression of hepatic CYP1A2 and 3A4 (24). Although silibinin decreased the glucuronidation of substrates based on rat liver microsomes (12), oltipraz was not metabolized to its glucuronide conjugate although the two metabolites (out of thirteen metabolites) of oltipraz formed their glucuronide conjugates (23). Thus, the $\mathrm{CL}_{\mathrm{NR}}$ of oltipraz was comparable between the two groups of rats (Table 1). After intravenous administration of the drugs together, the $\mathrm{Vd}_{\mathrm{ss}}$ of silibinin was significantly enlarged as compared with that observed after administration without oltipraz (Table 1). Although the exact reason for this is not clear, this was clearly not due to the increase in the free (unbound to plasma proteins) fractions of silibinin in the plasma in the rats with oltipraz; the plasma protein binding values of silibinin did not differ significantly between the groups with and without oltipraz.

After simultaneous i.v. administration of oltipraz and silymarin, the AUC values of unconjugated silibinin were smaller and those of conjugated and total silibinin were significantly greater than that of without oltipraz (Table 1). This could have been due to the increased formation of conjugates (glucuronidation and sulfation) of silibinin by oltipraz. It has been reported $(6,7)$ that oltipraz induced the activity of UGT in the rat liver. Although oltipraz has been reported to induce hepatic CYP2B2 in the rats (7), this contribution of oltipraz to AUC changes in unconjugated, conjugated, and total silibinin seems to be negligible, since the hepatic metabolism of silibinin was almost negligible in the rats (11). After simultaneous oral administration of oltipraz and silymarin, however, the AUCs (or $\mathrm{AUC}_{0-12 \mathrm{~h}}$ ) of unconjugated, conjugated, and total silibinin were comparable to the AUCs (or $\mathrm{AUC}_{0-12 \mathrm{~h}}$ ) of those without oltipraz (Tables 4 and 6). This could have been due to the slow absorption rate of silibinin possibly because of its poor water solubility (24); the plasma concentrations of unconjugated silibinin after oral administration with or without oltipraz (Figures 2B and 3B) were considerably lower than those after intravenous administration (Figure 1B). Therefore, the formation rates of conjugates of silibinin in the two groups of rats seem to be comparable because the plasma concentrations of silibinin (or the amount of silibinin that entered the liver) were close to the saturation level for the formation of conjugates. However, this could not be due to the changes in the GST and UGT activities and the increase in the CYP contents in the rat intestine by oltipraz. Since, it has been reported (6) that the GST and UGT activities and the CYP contents were not induced in the rats' small intestinal mucosa by oltipraz. The difference in the 
J Pharm Pharmaceut Sci (www.cspsCanada.org) 12 (1): 1-16, 2009

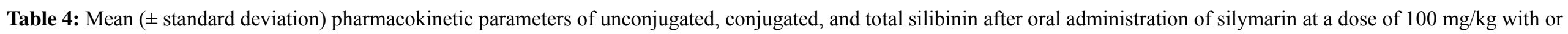
with simultaneous oral administration of oltipraz at a dose of $30 \mathrm{mg} / \mathrm{kg}$ to rats.

\begin{tabular}{|c|c|c|c|c|c|c|c|c|c|c|c|c|c|c|}
\hline \multirow{3}{*}{$\begin{array}{l}\text { Parameter } \\
\mathrm{AUC}^{\mathrm{a}}, \mu \mathrm{g} * \mathrm{~min} / \mathrm{mL}\end{array}$} & \multicolumn{7}{|c|}{ Without oltipraz $(n=12)$} & \multicolumn{7}{|c|}{ With oltipraz $(n=8)$} \\
\hline & \multicolumn{2}{|c|}{ Unconjugated } & \multicolumn{2}{|c|}{ Conjugated } & \multicolumn{3}{|c|}{ Total } & \multicolumn{2}{|c|}{ Unconjugated } & \multicolumn{2}{|c|}{ Conjugated } & \multicolumn{3}{|c|}{ Total } \\
\hline & 83.3 & $\pm \quad 78.5$ & 5260 & $\pm \quad 1470$ & 5470 & \pm & 1710 & 136 & \pm 81.4 & 5280 & \pm 1090 & 5580 & \pm & 1150 \\
\hline$T_{\max }, \min$ & \multicolumn{2}{|c|}{$15(15-120)$} & \multicolumn{2}{|c|}{$30(15-30)$} & \multicolumn{3}{|c|}{$30(15-30)$} & \multicolumn{2}{|r|}{15} & \multicolumn{2}{|c|}{$30(15-45)$} & \multicolumn{3}{|c|}{$30(15-60)$} \\
\hline$C_{\max }, \mu \mathrm{g} / \mathrm{mL}$ & 1.55 & $\pm \quad 0.97$ & 30.3 & $\pm \quad 9.20$ & 31.8 & \pm & 8.91 & 1.93 & \pm 0.852 & 28.5 & \pm 8.56 & 29.2 & \pm & 8.80 \\
\hline $\mathrm{t} 1 / 2, \min$ & & $\mathrm{NC}^{\mathrm{b}}$ & 694 & $\pm \quad 263$ & 773 & \pm & 372 & & $\mathrm{NC}$ & 630 & \pm 189 & 751 & \pm & 248 \\
\hline $\mathrm{CL}_{\mathrm{R}}, \mathrm{mL} / \mathrm{min} / \mathrm{kg}$ & & $\mathrm{NC}$ & & & 0.143 & \pm & 0.0905 & & $\mathrm{NC}$ & & & 0.113 & \pm & 0.114 \\
\hline $\begin{array}{l}\mathrm{Ae}_{0-24 \mathrm{~h}}, \% \text { silibinin } \\
\text { dose }\end{array}$ & 1.84 & $\pm \quad 0.923$ & 1.51 & $\pm \quad 0.909$ & 1.98 & \pm & 0.943 & 1.40 & $\pm \quad 1.29$ & 1.32 & $\pm \quad 1.14$ & 1.52 & \pm & 1.37 \\
\hline $\begin{array}{l}\mathrm{GI}_{24 \mathrm{~h}}, \% \text { silibinin } \\
\text { dose ) }\end{array}$ & & $\mathrm{BD}^{\mathrm{c}}$ & & $\mathrm{NM}^{\mathrm{d}}$ & 5.40 & \pm & 5.09 & & $\mathrm{BD}$ & & & 3.10 & \pm & 3.07 \\
\hline
\end{tabular}

${ }^{\mathrm{a}} \mathrm{AUC}_{0-12 \mathrm{~h}}$ for unconjugated silibinin; ${ }^{\mathrm{b}}$ Not calculable; ${ }^{\mathrm{c}}$ Below the detection limit; ${ }^{\mathrm{d}}$ Not measured.

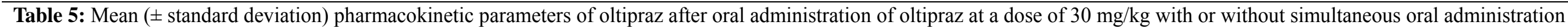
of silymarin at a dose of $100 \mathrm{mg} / \mathrm{kg} /$ day for 14 days to rats.

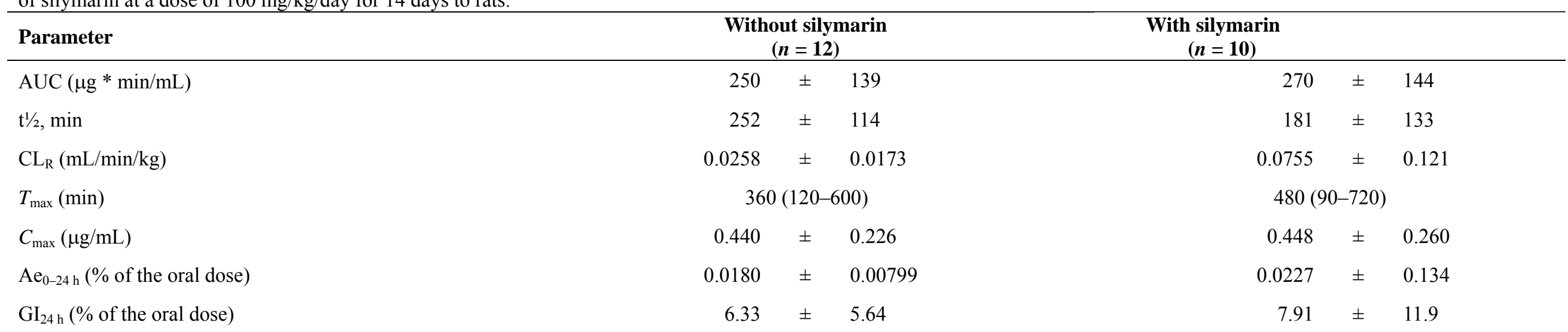

Values were not significantly different from each other $(p \geq 0.05)$. 
Table 6: Mean ( \pm standard deviation) pharmacokinetic parameters of unconjugated, conjugated, and total silibinin after oral administration of silymarin at a dose of $100 \mathrm{mg} / \mathrm{kg} / \mathrm{day}$ for 14 days with or without simultaneous oral administration of oltipraz at a dose of $30 \mathrm{mg} / \mathrm{kg}$ to rats.

\begin{tabular}{|c|c|c|c|c|c|c|c|c|}
\hline \multirow{3}{*}{$\begin{array}{l}\text { Parameter } \\
\mathrm{AUC}^{\mathrm{a}}(\mu \mathrm{g} * \mathrm{~min} / \mathrm{mL})\end{array}$} & \multicolumn{3}{|c|}{ Without oltipraz $(n=8)$} & \multicolumn{5}{|c|}{ With oltipraz $(n=10)$} \\
\hline & \multirow{2}{*}{$\begin{array}{c}\text { Unconjugated } \\
101 \pm 63.1\end{array}$} & Conjugated & Total & Unconjugated & Conjugated & \multicolumn{3}{|c|}{ Total } \\
\hline & & $4920 \pm 3340$ & $5020 \pm 3360$ & $104 \pm 68.6$ & $6160 \pm 1930$ & 6240 & \pm & 2030 \\
\hline$T_{\max }(\min )$ & $22.5(15-30)$ & $30(15-60)$ & $30(15-60)$ & $60(15-240)$ & $30(15-60)$ & & $(15$ & $-30)$ \\
\hline$C_{\max }(\mu \mathrm{g} / \mathrm{mL})$ & $0.695 \pm 0.558$ & $22.9 \pm 14.9$ & $23.5 \pm 15.4$ & $0.986 \pm 1.31$ & $31.8 \pm 17.7$ & 32.5 & \pm & 17.6 \\
\hline Terminal half life (min) & $\mathrm{NC}^{\mathrm{b}}$ & $\mathrm{NC}$ & $551 \pm 232$ & $\mathrm{NC}$ & $\mathrm{NC}$ & 617 & \pm & 244 \\
\hline $\mathrm{CL}_{\mathrm{R}}(\mathrm{mL} / \mathrm{min} / \mathrm{kg})$ & $\mathrm{NC}$ & $\mathrm{NC}$ & $0.0982 \pm 0.113$ & $\mathrm{NC}$ & $\mathrm{NC}$ & 0.123 & \pm & 0.0802 \\
\hline $\begin{array}{l}\mathrm{Ae}_{0-24 \mathrm{~h}} \\
\text { (\% of the silibinin dose) }\end{array}$ & $2.13 \pm 2.13$ & $2.40 \pm 4.02$ & $2.25 \pm 4.04$ & $0.552 \pm 0.309^{c}$ & $1.68 \pm 1.62$ & 2.19 & \pm & 1.78 \\
\hline $\begin{array}{l}\mathrm{GI}_{24} \mathrm{~h} \\
\text { (\% of the silibinin dose) }\end{array}$ & $\mathrm{BD}^{\mathrm{d}}$ & $\mathrm{NM}^{\mathrm{e}}$ & $4.95 \pm 3.64$ & $\mathrm{BD}$ & NM & 7.70 & \pm & 4.74 \\
\hline
\end{tabular}


Table 7: Mean ( \pm standard deviation) pharmacokinetic parameters of total silibinin after single oral administration of silymarin at a dose of $100 \mathrm{mg} / \mathrm{kg}$ to rats with bile duct cannulation.

\begin{tabular}{lc}
\hline Parameter & $\begin{array}{c}\text { Total silibinin } \\
(\boldsymbol{n}=\mathbf{1 0})\end{array}$ \\
\hline $\mathrm{AUC}_{0-24 \mathrm{~h}}$ & $3890 \pm 3160$ \\
$\left(\mu \mathrm{g}^{*} \mathrm{~min} / \mathrm{mL}\right)$ & $420(30-1440)$ \\
$T_{\max }(\mathrm{min})$ & $5.57 \pm 4.81$ \\
$C_{\max }(\mu \mathrm{g} / \mathrm{mL})$ & $4.16 \pm 3.59$ \\
$\mathrm{Ae}_{0-24 \mathrm{~h}}(\%$ of the oral silibinin dose $)$ & $28.5 \pm 10.8$ \\
$\mathrm{GI}_{24 \mathrm{~h}}(\%$ of the oral silibinin dose $)$ & \\
\hline
\end{tabular}

formation of sulfate conjugates of salicylamide due to the difference in the absorption rate has also been reported in healthy human subjects $(25) ; 29.7 \%$, $31.8 \%, 31.8 \%$, and $73.0 \%$ of the oral dose of salicylamide were formed into sulfate conjugates after the administration of $1 \mathrm{~g}$ solution, $1 \mathrm{~g}$ suspension, $0.6 \mathrm{~g}$ solution, and $1 \%$ pellet of salicylamide, respectively.

A second peak and/or multiple peaks appeared in the plasma concentration-time profiles of total silibinin after the oral administration of silymarin to the rats without bile duct cannulation; 7 out of 12 rats and 5 out of 8 rats for the oral administration of silibinin with (Figure 3D) and without (Figure 2D) 14 days oral administration of oltipraz, respectively. The second peak and/or the multiple peaks of total silibinin also appeared after the oral administration of silibinin alone with bile duct cannulation; 10 out of 10 rats (Figure 4). The appearance of a second peak and/or multiple peaks are not readily apparent in Figures 2-4, however, since the concentrations of total silibinin in Figures 2-4 refer to the mean values of the plasma concentrations in each rat, with different peak times and different concentrations. The abovementioned data suggest that the second peak and/or the multiple peaks phenomena of total silibinin were not mainly due to enterohepatic recycling. The possible reasons for the multiple peaks phenomenon due to irregular or slow blood partition of drugs between the plasma and blood cells, the enterohepatic recycling of drugs, the rapid uptake of drugs in the tissues followed by the late release of the drugs from the tissues to the blood, and/or the gastric emptying pattern of drugs have been discussed $(26,27)$.

\section{CONCLUSIONS}

After single intravenous administration of the drugs together, increase in the formation of conjugates (glucuronidation and sulfation) of silibinin induced by oltipraz caused the significantly smaller AUC of unconjugated silibinin and significantly greater AUCs of conjugated and total silibinin. After simultaneous oral administration of the drugs, however, the AUCs (or $\mathrm{AUC}_{0-12 \mathrm{~h}} \mathrm{~S}$ ) of unconjugated, conjugated, and total silibinin were not affected by oltipraz.

Silymarin is mainly administered orally for the treatment and prevention of various liver diseases including cirrhosis, chronic hepatitis, and alcoholinduced fatty liver. Orally administered oltipraz is being evaluated in phase II clinical study in South Korea. If the present rat data could be extrapolated to humans, a change in the dosage regimen of oral silymarin and oltipraz does not seem to be required. Studies on human are needed to prove the above hypotheses.

\section{ACKNOWLEDGMENTS}

This study was supported in part by a grant from the Korea Ministry of Health \& Welfare, Korea (01-PJ2 PG4-PT01-0027).

\section{REFERENCES}

[1] Bueding, E., Dolan, P., Leroy, J.P., The antischistosomal activity of oltipraz. Res Commun Chem Pathol Pharmacol, 37:293303, 1982.

[2] Primiano, T., Egner, P.A., Sutter, T.R., Kelloff, G.J., Roebuck, B.D., Kensler, T.W., Intermittent dosing with oltipraz: relationship between chemoprevention of aflatoxininduced tumorigenesis and induction of glutathione S-transferases. Cancer Res, 55:4319-4324, 1995.

[3] Kang, K.W., Kim, Y.G., Cho, M.K., Bae, S.K., Kim, C.W., Lee, M.G., Kim, S.G., 
Oltipraz regenerates cirrhotic liver through CCAAT/enhancer binding protein-mediated stellate cell inactivation. FASEB J, 16:19881990, 2002.

[4] Bae, S.K., Lee, S.J., Kim, T., Kim, J.W., Lee, I., Kim, S.G., Lee, M.G., Pharmacokinetics and therapeutic effects of oltipraz after consecutive or intermittent oral administration in rats with liver cirrhosis induced by dimethylnitrosamine. J Pharm Sci, 95: 985-997, 2006.

[5] Bae, S.K., Lee, S.J., Kim, Y.H., Kim, T., Lee, M.G., Effect of enzyme inducers and inhibitors on the pharmacokinetics of oltipraz in rats. J Pharm Pharmacol, 57:443-452, 2005.

[6] Vargas, M., Lamb, J.G., Franklin, M.R., Phase II-selective induction of hepatic drugmetabolizing enzymes by oltipraz 5-(2pyrazinyl)-4-methyl-1,2-dithiol-3-thione, 1,7-phenanthroline and 2,2'-dipyridyl in rats is not accompanied by induction of intestinal enzymes. Drug Metab Dispos, 26: 91-97, 1998.

[7] Buetler, T.M., Gallagher, E.P., Wang, C., Stahl, D.L., Hayes, J.D., Eaton, D.L., Induction of phase I and phase II drugmetabolizing enzyme mRNA, protein, and activity by BHA, ethoxyquin, and oltipraz. Toxicol Appl Pharmacol, 135:45-57, 1995.

[8] Miguez, M.P., Anundi, I., Sainz-Pardo, L.A., Lindros, K.O., Hepatoprotective mechanism of silymarin: no evidence for involvement of cytochrome P450 2E1. Chem Biol Interact, 91:51-63, 1994.

[9] Volate, S.R., Davenport, D.M., Muga, S.J., Wargovich, M.J., Modulation of aberrant crypt foci and apoptosis by dietary herbal supplements (quercetin, curcumin, silymarin, ginseng and rutin). Carcinogenesis, 26:1450-1456, 2005.

[10] Bulles, H., Bulles, J., Krumbiegel, G., Mennicke, W.H., Nitz, D., Studies of the metabolism and excretion of silybin in the rat. Arzneimittelforschung, 25:902-905, 1975.

[11] Gunaratna, C., Zhang, T., Application of liquid chromatography-electrospray ionization-ion trap mass spectrometry to investigate the metabolism of silibinin in human liver microsomes. $J$ Chromatogr $B$ Analyt Technol Biomed Life Sci, 794:303-310, 2003.

[12] D'Andrea, V., Perez, L.M., Sanchez Pozzi, E.J., Inhibition of rat liver UDP- glucuronosyltransferase by silymarin and the metabolite silibinin-glucuronide. Life Sci, 77:683-692, 2005.

[13] Kim, S.H., Choi, Y.M., Lee, M.G., Pharmacokinetics and pharmacodynamics of furosemide in protein-calorie malnutrition. $J$ Pharmacokinet Biopharm, 21:1-17, 1993.

[14] Bae, S.K., Kim, J.W., Kim, Y.H., Kim, Y.G., Kim, S.G., Lee, M.G., Hepatic and intestinal first-pass effects of oltipraz in rats. Biopharm Drug Dispos, 26:129-134, 2005.

[15] Shim, H.J., Lee, E.J., Kim, S.H., Kim, S.H., Yoo, M.H., Kwon, J.W., Kim, W.B., Lee, M.G., Factors influencing the protein binding of a new phosphodiesterase $\mathrm{V}$ inhibitor, DA-8159, using an equilibrium dialysis technique. Biopharm Drug Dispos, 21:285-291, 2000.

[16] Boudinot, F.D., Jusko, W.J., Fluid shifts and other factors affecting plasma protein binding of prednisolone by equilibrium dialysis. J Pharm Sci, 73:774-780, 1984

[17] Øie, S., and Guentert, T.W., Comparison of equilibrium time in dialysis experiments using spiked plasma or spiked buffer. $J$ Pharm Sci; 71:127-128, 1982

[18] Bae, S.K., Bu, S.C., Kim, E.J., Kim, S.H., Kim, S.G., Lee, M.G., Determination of a chemopreventive agent, oltipraz, in rat plasma and urine by high-performance liquid chromatography. Res Commun $\mathrm{Mol}$ Pathol Pharmacol, 110:133-138, 2001.

[19] Christensen, R.G., Malone, W., Determination of oltipraz in serum by highperformance liquid chromatography with optical absorbance and mass spectrometric detection. J Chromatogr, 584:207-212, 1992.

[20] Rickling, B., Hans, B., Kramarczyk, R., Krumbiegel, G., Weyhenmeyer, R., Two high-performance liquid chromatographic assays for the determination of free and total silibinin diastereomers in plasma using column switching with electrochemical detection and reversed-phase chromatography with ultraviolet detection. $J$ Chromatogr B Biomed Appl, 670:267-277, 1995.

[21] Chiou, W.L., Critical evaluation of potential error in pharmacokinetic studies using the linear trapezoidal rule method for the calculation of the area under the plasma level-time curve. $J$ Pharmacokinet Biopharm, 6:539-546, 1978. 
[22] Gibaldi, M., Perrier, D., Pharmacokinetics. 2nd ed. Marcel-Dekker, New York, NY, USA, 1982.

[23] Bieder, A., Decouvelaere, B., Gaillard, C., Depaire, H., Heusse, D., Ledoux, C., Lemar, M., Leroy, J.P., Raynaud, L., Snozzi, C., Gregoire, J., Comparison of the metabolism of oltipraz in the mouse, rat and monkey and in man. Distribution of the metabolites in each species. Arzneimittelforschung, 33:1289-1297, 1983.

[24] Kosina, P., Maurel, P., Ulrichova, J., Dvorak, Z., Effect of silybin and its glycosides on the expression of cytochromes P450 1A2 and $3 \mathrm{~A} 4$ in primary cultures of human hepatocytes. $J$ Biochem Mol Toxicol, 19:149-153, 2005.

[25] Levy, G., Dose dependent effects in pharmacokinetics. In: Tedeshchi, D.H., Tedeschi, R.E., (Ed), Importance of
Fundamental Principles in Drug Evaluations, Raven press, New York, NY, USA, pp. 141-172, 1968.

[26] Lee, S.H., Lee, M.G., Pharmacokinetics and pharmacodynamics of azosemide after intravenous and oral administration to rats: absorption from various GI segments. $J$ Pharmacokinet Biopharm, 24:551-568, 1996.

[27] Lee, S.H., Lee, M.G., Kim, N.D., Pharmacokinetics and pharmacodynamics of bumetanide after intravenous and oral administration to rats: absorption from various GI segments. $J$ Pharmacokinet Biopharm, 22:1-17, 1994. 